\title{
THE CONTEXTUAL COMPONENT IN A DIALOGIC FDG ${ }^{1}$
}

\author{
J. Lachlan Mackenzie
}

\begin{abstract}
Functional Discourse Grammar (FDG) has to date been explicitly oriented to modelling the grammar of the individual speaker, with the Contextual Component being seen as supportive. If FDG is re-interpreted as dialogic, the Contextual Component emerges as being shared by all interactants in the dialogue and as playing a central role in interaction. A dialogic FDG is proposed to provide a basis for understanding the role of interpersonal alignment in conversation as well as reflecting developments in psycholinguistics. It is applied to the analysis of eight extracts from a dialogue transcription in Eggins and Slade (2005).
\end{abstract}

Keywords: Functional Discourse Grammar; Dialogue; Priming; Contextual Component; Interpersonal alignment; Conversation.

\section{Introduction}

The idea to be pursued in this paper is that the Contextual Component should be modelled as a shared, mutually accessible and dynamically developing storage facility for grammatical representations in the framework of a dialogic Functional Discourse Grammar (FDG). It is possible that the Contextual Component, in addition to storing representations from the Grammatical Component, should be seen as also holding longer-term information about the ongoing situation (cf. Hengeveld and Mackenzie, this volume); the Contextual Component should perhaps be ascribed even broader functions, encompassing such matters as the nature and purpose of the current interaction as well as the socio-cultural environment in which it is taking place (cf. Connolly, this volume). The present paper takes no stand on these questions, focusing on the function of the Contextual Component in modelling and understanding interpersonal alignment in dialogue as manifested in evidence from transcriptions of dialogue that indicates how conversationalists extensively reuse their own and their partner's formulations and encodings. This phenomenon, the prevalence of which has become apparent in recent psycholinguistic work, cannot be understood without assuming a Contextual

\footnotetext{
${ }^{1}$ The research for this article was partially financed by the research project INCITE09 204155 PR (Autonomous Government of Galicia) and FFI2010-19380/FILO (Spanish Ministry of the Economy and Competitivity). The author wishes to thank all the members of the Barcelona Workshop on the Contextual Component of Functional Discourse Grammar (2011) for their invaluable comments on earlier versions of this paper.
} 
Component in which grammatical representations are stored for possible partial reuse. An FDG that considers linguistic expressions independently of their dialogic context inevitably remains blind to the omnipresence of the linguistic recycling that results from interaction.

The paper divides into 7 sections. Section 2 discusses the nature of FDG as presented by Hengeveld and Mackenzie (2008), emphasizing its orientation to the individual language user (hitherto primarily the speaker) and explicating the notion of 'dynamic implementation'. Section 3 concentrates on the position of the Contextual Component in FDG and presents a basis for understanding it as being shared by dialogists. Section 4 then sets out a proposal for a dialogic FDG and explains its dynamic implementation, with links to the notion of interpersonal alignment. Section 5 discusses psycholinguistic work that is relevant to the broader interpretation of the extended model, briefly examining the notion of 'egocentric processing' as an alternative to more partner-oriented approaches to the Contextual Component. Section 6 discusses eight extracts from an extended transcription of dialogue in the light of the dialogic model of FDG. The paper ends with a brief conclusion (Section 7). The full transcript of the dialogue from which the extracts are taken is given in an Appendix.

\section{The FDG model and the speaker: Dynamic implementation}

Let us first consider the nature of the model of FDG defended in Hengeveld and Mackenzie (2008). There it is the individual language user (the speaker) who is explicitly held to be central to the theory:

FDG starts with the speaker's intention and then works down to articulation. This is motivated by the assumption that a model of grammar will be more effective the more its organization resembles language processing in the individual. (Hengeveld and Mackenzie 2008: 1-2; emphases added)

The major orientation in both linguistics and psycholinguistics over the past decades has been to the individual, in linguistics at least since Chomsky's (1965: 1) "ideal speakerlistener" and in psycholinguistics for reasons of experimental convenience - it is simply much easier to control for interfering variables and avoid "exuberant responding" (Bock 1996: 407) when working with an individual subject in the laboratory. The initial presentation of FDG, in explicitly mentioning the individual, is thus following in welltrodden footsteps. Although their presentation is oriented to the individual and specifically to the speaker, Hengeveld and Mackenzie (2008: 2) do make it clear that the model could be 'turned on its head and understood as a parsing or comprehension model' (cf. Giomi, this volume); an FDG oriented to the individual addressee is thus accepted as an imaginable alternative perspective on the theory.

Despite potentially taking a double perspective on interaction - with orientation either to the speaker or to the addressee - the original presentation of FDG does not attempt to encompass dialogue. However, many details of the model do imply an interactional perspective in which encoding is complemented by decoding and 
formulation is complemented by reconstruction. ${ }^{2}$ This is apparent in the very name of the Interpersonal Level and in many of the internal properties of that level: Consider in particular the alternation of Initiating and Reactive Moves (Hengeveld and Mackenzie 2008: 50) or the presence at the Illocutionary Layer of two participant functions, those of Speaker and Addressee (2008: 84). As I hope to show, an expansion of the theory to encompass dialogue will not do violence to the fundamentals of FDG. What is more, such a move will allow FDG to hook up with relevant traditions in both linguistics and psycholinguistics that have re-oriented their perspective to dialogue between individual language users: One may think of the research into the interface between conversation analysis and grammar (Ford, Fox and Thompson 2002), the psycholinguistic work on the negotiation of reference (Clark and Wilkes-Gibb 1986) or the examination of syntactic change resulting from routinization of alignment patterns found in dialogue (Kempson and Cann 2007). ${ }^{3}$ The specific aim of this paper is, accordingly, to explore the repercussions of a dialogic view for our understanding of the Contextual Component within the framework of FDG.

Before progressing, however, it is important to return to the expressions 'starts with' and 'work down to' in the quotation from Hengeveld and Mackenzie (2008) given above and to explicate these in the framework of the notion of 'dynamic implementation'. This notion is most extensively developed by Hengeveld (2005), who refers to earlier work on dynamic implementation by Bakker $(1999,2001,2005)$ but also distances himself from that work. Whereas Bakker (2005: 5) saw his dynamic expression model, as he called it, as contributing to "a model of the language user, arguably even distinguishing between a model of the spreaker [sic] and one of the addressee", Hengeveld regards FDG as a model of grammar and therefore rejects the ambition of creating a 'speaker model', i.e. a model of real-time processes in the production of language. For Hengeveld, dynamic implementation is something quite different: It is a matter of making fully explicit the relations among (and within) the various components of the overall theory of verbal interaction.

In this dynamic implementation, notationally represented by pathways defined by single- or double-headed arrows, notions of 'before and after' or 'first and second' are accordingly to be understood as "the sequence of steps that the analyst must take in understanding and laying bare the nature of a particular phenomenon" (Hengeveld and Mackenzie (2008: 2; emphasis added). The aim is thus to clarify the logic of the relations among the layers, levels and components and not to mimic sequence in the real time of language production. At best, the arrows indicate sequence in the real time of the analyst.

Although not a speaker model, FDG has undeniably been strongly influenced by psycholinguistic findings about speaking, specifically those of Levelt (1989), with a strong overlap between the terminology that he uses to denominate real-time, sequenced psychological processes (such as conceptualizer, formulator, grammatical encoder, phonological encoder and articulator) and the FDG terminology that names operations

2 'Reconstruction' is my term for the addressee's creation of Representational and Interpersonal Levels on the basis of what he has decoded.

${ }^{3}$ See Linell (2007), too, for an overview of 'dialogism' as "a counter-theory to monologism, which is associated with individualism" (2007: 605) and Weigand (2010: 59-61) for a view of humans as 'dialogic individuals'. 
and processes which are part of the analyst's algorithm. Indeed, the very efficiency of the psychological processes unearthed by Levelt has inspired certain theoretical choices such as for example the Depth-First Principle according to which information from a higher level is sent down to a lower level as soon as the necessary input for the lower level is available (Hengeveld and Mackenzie 2008: 24). Compare Levelt's (1999: 88) finding that the "next processing component in the general flow of information can start working on the still incomplete output of the current processor". This is how we are to understand the above-quoted statement that "a model of grammar will be more effective the more its organization resembles language processing" (Hengeveld and Mackenzie 2008: 1-2). This 'general analogy' (Hengeveld and Mackenzie 2008: 25) between the inner workings of FDG and the processes of language production should, however, not mislead us into understanding FDG as representing real-time processes.

\section{The Contextual Component as a 'public' component}

The full FDG approach to verbal interaction implies the interplay of four components. Corresponding to the speaker's intention and articulation there is a Conceptual Component and an Output Component respectively. In the dynamic implementation of the theory, the Conceptual Component feeds the Grammatical Component, which in turn feeds the Output Component. The Contextual Component, by contrast, has no direct role to play in the unidirectional movement from the Conceptual Component through the Grammatical Component to the Output Component. Rather, it is modelled and graphically displayed as standing alongside the other Components, playing a supportive role. In a direction orthogonal to the flow from Conceptual to Output Component, all the four levels of the Grammatical Component feed the Contextual Component; and conversely, the Contextual Component can feed into each of the three operations (Formulation; Morphosyntactic Encoding; Phonological Encoding) in the Grammatical Component. If we interpret the dynamic implementation of FDG, as we are encouraged to do, as being in correspondence to an individual speaker, the Conceptual and Output Components clearly pertain to the speaker alone and this must also apply to the Contextual Component.

However, from a viewpoint that encompasses dialogic interaction, a clear difference emerges between the Conceptual and Output Components on the one hand and the Contextual Component on the other. Whereas the information in the Conceptual Component models the speaker's 'private' knowledge and the information in the Output Component models how an individual phonetically interprets the Phonological Level of the grammar (through the translation of digital representation into analogue form), the information in the Contextual Component is necessarily 'public', in the sense of being available to all participants in the ongoing interaction. In a model oriented to dialogue, simply placing two or more individual four-component systems next to each other, each with its own ('private') Contextual Component, is not enough, since there would then be no explicit recognition of the presence of dialogic interaction; the overlap or identity of the interactants' Contextual Components would be a matter of chance rather than following automatically from the model. However, if we explicitly permit the Contextual Component to be shared by the dialogue participants, the result will both retain the sophistication of FDG's internal organization and explicitly model grammar 
as a component of verbal interaction, which remains the goal of FDG (Hengeveld and Mackenzie 2008: 1).

It may be objected that it is not clear where a shared Contextual Component would be 'located'. Individual interactants, after all, have separate brains in which language is processed and contextual information is retained. The assumption of this paper, however, is that participation in a dialogue entails an overlap of minds: In the case of individuals who know each other very well (as in the dialogue analysed in Section 6), there is an extensive pre-existent 'shared mind'; ${ }^{4}$ where strangers are interacting, the most obvious aspects of context are initially shared and as the conversation progresses, more and more comes to be shared. In essence, this is what underlies Grice's (1975) Co-operative Principle, which applies to all types of interaction, from the intimate conversation of old friends to an angry row between strangers.

Another possible objection is that malfunctions in conversation may cause the content of one interactant's Contextual Component to differ from that of another interactant. In practice, this may indeed happen, but in modelling we may abstract from such malfunctions, as we do in a monologue model; what is more, when misalignments do occur they are typically corrected by interactants within the framework of conversational co-operation without requiring explicit discussion (see Section 6 for an example).

The primary advantage of assuming a shared Contextual Component is that it permits an explicit link between interactants and thus contributes to strengthening FDG as an integral part of a model of verbal interaction. This link, it will be argued, provides a basis for understanding various aspects of interaction that are relevant for understanding the interplay of grammatical and contextual factors in determining linguistic forms. By assuming a stratified Contextual Component (following Hengeveld and Mackenzie, this volume), moreover, we will be able to give a precise account of that grammar-context interplay.

\section{A proposal for a dialogic FDG}

Figure 1 (below) shows in outline a proposal to adapt the existent FDG model to allow the Contextual Component to be shared by the participants in a dialogue. The internal properties of the Conceptual, Grammatical and Output Components are identical to those currently assumed in monologic FDG. Figure 1 sets out the basis for the analysis - according to 'dynamic implementation' in the sense explicated in Section 2 above - of two successive utterances in a dialogue, by Participants A (female) and B (male) respectively. The treatment of Participant A's utterance is situated above that of Participant B's.

Each Participant has his/her own Conceptual Component (situated at the top of the figure), which in the case of Participant A provides input to her Grammatical Component for the first utterance; this sparks off a series of operations to be spelled out

\footnotetext{
${ }^{4}$ For philosophical examination of the 'shared mind', see Clark (2008); cognitive neuroscientists Hasson et al. (2012) similarly talk of shifting from a single-brain to a multi-brain frame of reference and of 'brain-to-brain coupling'.
} 
below. Participant B's Conceptual Component (in terms of dynamic implementation) then provides input to his Grammatical Component, the output of which is a second utterance. Figure 1 shows only two participants for reasons of clarity: A model could be built, mutatis mutandis, for multi-party dialogues.

Let us now consider the pathways for each Participant in a dialogue. Each speaking Participant's Grammatical Component (shown in Figure 1 in highly simplified form) feeds into the Output Component which generates an audible message (represented as an irregular wave form); this is picked up by the Input Component of the other Participant and feeds into the current Addressee's Grammatical Component, with its four levels, again represented in highly simplified form (see Giomi, this volume, for more detail). The content of each of the four levels of the Speaker's Grammatical Component is registered in the Contextual Component, ${ }^{5}$ as is the content of the four levels of the Addressee's Grammatical Component. The result is a shared Contextual Component. Notice that the Contextual Component is divided into four strata, each of which corresponds to a level in grammatical analysis.

The most striking detail of the figure, perhaps, is the set of arrows leading from each stratum of the Contextual Component to the corresponding level of the Grammatical Component for the next utterance. This is designed to show an essential aspect of the proposal, the attempt to represent the effect of interpersonal alignment by means of arrows leading from the strata of the Contextual Component as configured by Utterance $U$ to the four grammatical levels characterizing the Grammatical Component as configured at Utterance $U+1$. The intention is to represent (in oversimplified form) the fact, to be expanded on below, that the pragmatic, semantic, morphosyntactic and phonological properties of prior utterances, held at four separate strata in the shared Contextual Component, all influence the operations of Formulation and Encoding in subsequent utterances. Note, moreover, that the processes are to be understood as fully automatic: The interpersonal alignment that is being modelled here is an entirely unconscious element of language production in dialogue and thus deserves to be modelled in a dynamic implementation of the model in just the same way as other unconscious processes that involve the interplay of the Grammatical and Contextual Components.

It is important to stress that the Contextual Component does not represent the personal meaning of what has been said for either Participant A or Participant B. It is simply a record of the four analyses. Just as Formulation "has the task of translating conceptual configurations into the semantic and pragmatic distinctions available within a specific language" (Hengeveld and Mackenzie 2008: 8) - and similar remarks apply to Encoding - the Contextual Component, too, is restricted to the distinctions that apply in the language being spoken. In those respects in which Encoding underrepresents the meanings distinguished at the Representational and Interpersonal Levels, notably relations of coreference, the Grammatical Component must be able (in ways still to be clarified) to consult the Contextual Component to determine the intended anaphoric relations. In this way, the Contextual Component creates a shared space for the "joint project" (Clark 1996: 191-220) of communication from which no one who enters into interaction can opt out.

${ }^{5}$ In psycholinguistic terms, the Speaker's registration of her own grammatical levels in the Contextual Component may be seen as the basis for self-monitoring (Levelt 1989: 13-14). 


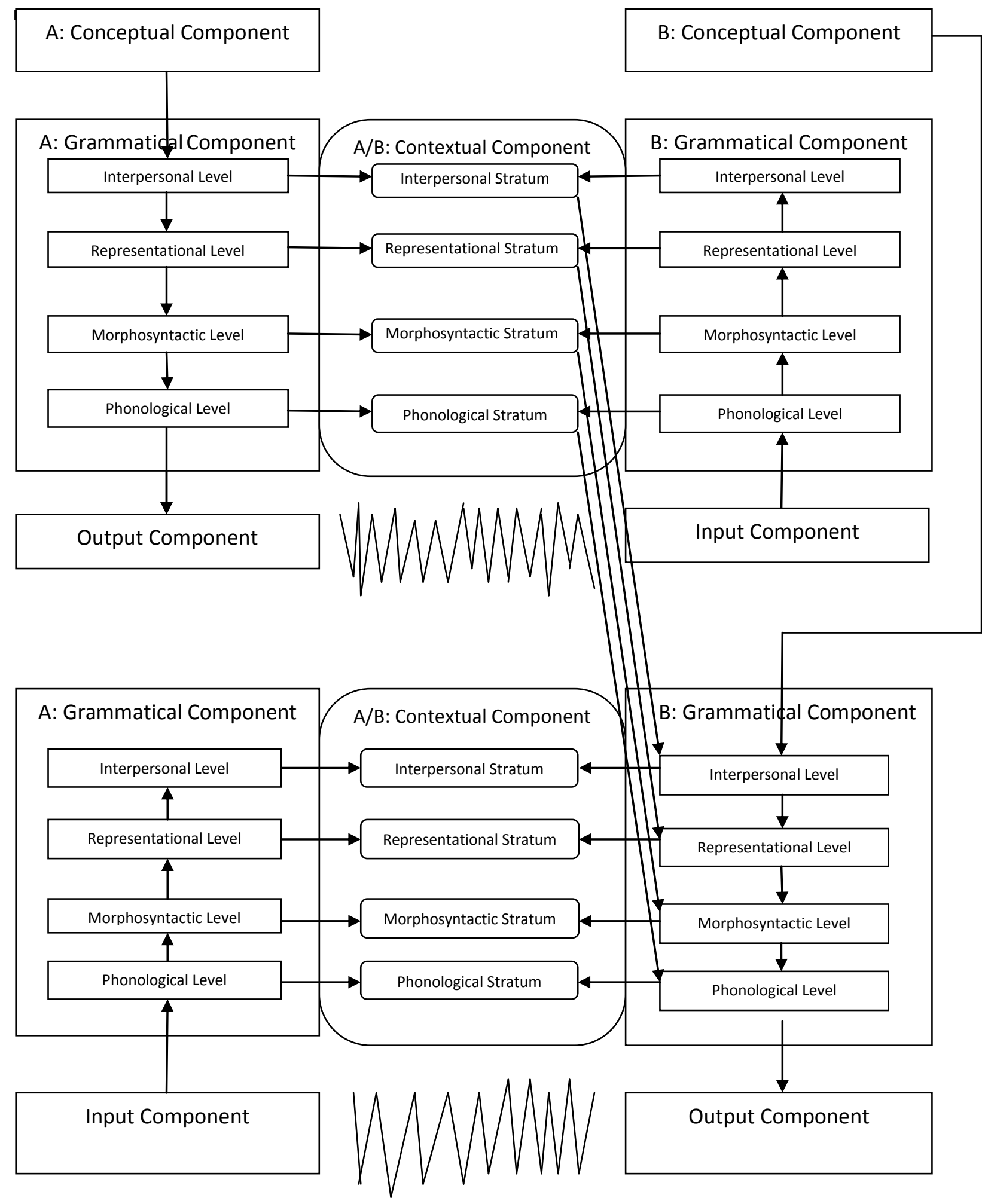

Figure 1 
Assuming the correctness, at least in outline, of Figure 1's interpretation of the Contextual Component as a shared record of the four levels of grammatical analysis, let us turn to the innovative proposal to have these four levels influence Formulation and Encoding in subsequent utterances. This proposal is inspired by the notion of interpersonal alignment, invoked by Pickering and Garrod (2004) to explain the phenomenon that utterances within a dialogue tend to resemble preceding utterances in ways that can only be understood as resulting from influence of the latter on the former. The notion is to be interpreted in the broader context of human interaction: It is for example common knowledge that laughter is contagious and that one person's yawn will tend to set everyone else yawning. More technically, recent neurological work on mirror neurons (Iacoboni 2005, 2008) suggests that the mimetic impulse is hard-wired: When we observe an activity, the neurons that would fire if we ourselves were carrying out the activity also fire:

[S]uch motoric processes as eye-gaze, body torque, rhythm attunement, and simultaneous gestures are part of a social interaction (rather than a "software program" as classic cognitivism advocates) that is critically dependent on the motor system's facility for temporal orientation and organization of sequence and, I propose, is also dependent on (and plausibly even deriving from) the action recognition or mirror system. (Iacoboni 2005: 94)

Generally, other neurons inhibit imitation, but not always: We barely consciously tap our feet to the rhythm of music, just as we cannot help mimicking each other's movements when dancing. It seems reasonable to assume that it is this mimetic impulse that underlies interpersonal alignment.

Much of the linguistic evidence for interpersonal alignment comes from the inspection of dialogue transcripts, in which it is clear that each interactant's contributions are influenced, constrained, or primed by various properties of his/her partner's earlier utterances (For an example of a transcription analysed from the viewpoint of a dialogic FDG, see Mackenzie 2012; for further instances, see Section 6 below). To an extent that would not be predicted by having the impetus for linguistic activity come from the individual Conceptual Component alone, dialogists recycle their own and each other's formulations, accommodating their speech to one another and as a result coming to feel togetherness in communication. This is manifested in repetitions, ellipses, parallelisms, shared formulations, overlapping lexical choices, common morphosyntactic preferences and prosodic-phonological realizations, as well as in the completion of each other's incomplete utterances and the leaving incomplete of utterances that clearly have already been understood. All of these phenomena have been extensively documented by analysts of dialogue (Tannen 2006; Poesio and Rieser 2010), and it has been claimed (e.g. by Kempson and Cann 2007: 87) that these characteristics of dialogue ensure the smooth processing of language in conversation.

In addition, there is evidence from the study of 'referential communication tasks' in laboratory situations that conversationalists share their creativity through the Contextual Component: When one interactant provides a name for an object or shape that does not have an obvious name, for example a tangram, the other interactant will tend to accept that name, setting up a 'routine' that will last at least as long as the conversation requires that name. Thus Schober and Brennan (2003) refer to an unpublished 2000 conference paper by Brennan reporting on an experimental situation 
in which one dialogist referred to a particular tangram as a 'monk', a routine that was tacitly accepted by both conversational partners for the remainder of the interaction.

In the approach to FDG proposed here, formulation/encoding and decoding/ reconstruction are mutually supported processes. This is designed to reflect the insight that the language user who encodes a message has, with the exception of dialogue-initial contributions, just benefited from decoding another, which in all its detail - its structure at each of the levels and possibly even its phonetic characteristics - gives her inspiration in terms of pragmatic, semantic, morphosyntactic and phonological structure as well as lexical choice. This direct help is strengthened by the other dialogist, who responds to her communicative initiative with feedback and backchannels, as well as looks of understanding or confusion and corresponding gestures. There is of course an undeniable creative element to everything we say, and this comes from our individual Conceptual Component. But the large degree of overlap in dialogist's speech contributions can best be understood by assuming a shared Contextual Component. Language users are accommodators as much as they are creators; in the words of Ferreira and Bock (2006: 1011), "though linguistic performance is quintessentially creative, it can also be surprisingly recapitulative". 6

The question arises whether the impact of the Contextual Component upon the workings of the grammar is 'systematic' in the sense of Hengeveld and Mackenzie (this volume). Influence that is not systematic, after all, is in their view not relevant to the workings of FDG. It is of course true that only some of the information stored in the Contextual Component can be argued to impinge upon later utterances and that it is not predictable which information will do so. In addition, there are many cases where it is hard or impossible to show whether a particular form is attributable to functional or to contextual factors (Mackenzie 2012). The most convincing examples of contextual influence therefore occur when contextual factors overrule functional ones, e.g. when a passive construction is primed by earlier instances of passive where an active would, from a functional perspective, have been more appropriate. However, what we have here is a typical example of the interaction of independent systems: In any individual case, these may work in parallel to yield the same output or one will trump the other. It may be impossible to predict how the systems will interact, but the analyst can detect the presence of the interaction retroactively. ${ }^{7}$

The implication for FDG is that verbal interaction should no longer be modelled simply as the transfer of information from speaker to addressee, a view that has hitherto been dominant in descriptions of the theory. This view has emphasized the individual speaker's objective of effecting a change in the 'pragmatic information' (cf. Hengeveld and Mackenzie 2008: 107) of the addressee. While it is undeniable that language users have individual aims, these cannot be achieved individually, but only by working together on the communal aim of participating in the joint creation of a consensus about the ongoing dialogue. The shared Contextual Component arises from this joint project.

\footnotetext{
${ }^{6 .}$ See Mackenzie (2012) for a discussion of what he calls Bolinger's problem, the impossibility of telling whether an unremarkable sentence like I went home is a result of innovation or of repetition.

${ }^{7}$ See Bargh (2006: 158-164) for discussion of what he calls the 'reduction problem', "the puzzle of how ... parallel influences get channeled back through the bottleneck of having to act in real time" and a suggestion that solutions may be found in "extant models of language production" (2006: 161).
} 


\section{Psycholinguistic considerations}

The psycholinguistic back-up for a shared, overlapping Contextual Component derives originally from extensive experimental work on linguistic 'priming'. A large body of research, summarized in Pickering and Ferreira (2008), has shown that individuals in experimental situations make continual use of their earlier formulation and encoding options; the earlier occurrences are said to 'prime' the later ones. This reuse may take the form of full or partial repetition, an insight that has been reflected in linguistic work, for example in the study of 'cohesion', from Halliday and Hasan (1976) to GómezGonzález (2011), which explicitly looks at dialogue with a view to 'lexical cohesion'. But it was the research of Pickering and Garrod (2004), to whom we owe the notion of interpersonal alignment, that explicitly showed, with reference to earlier findings by Branigan, Pickering and Cleland (2000), that priming applies not only within the individual but also across dialogists, with little detectable difference between autopriming (the effect of one's own earlier utterances) and allo-priming (the effect of the conversation partner's earlier utterances). It is this result that provides psycholinguistic backing for viewing the Contextual Component as a shared resource for conversationalists as they interact.

An essential property of priming and interpersonal alignment is that they are subconscious processes. In this sense they resemble grammatical processes, which are essentially automatic processes guided by procedural memory, which lies below consciousness. As is well understood, there is no direct relation between conscious, strategic decisions and grammatical or lexical operations. Even where the communicative strategy is quite apparent, as when a caretaker decides to simplify her speech to an infant, a native speaker decides to adapt his speech for a foreigner, or a New Yorker shows sensitivity to the difference between giving directions to another New Yorker as against an out-of-towner (cf. Isaac and Clark 1987), none of these decisions stands in a direct cause-and-effect relationship to specific linguistic forms.

The proposal is thus that each individual, by virtue of his/her participation in a dialogue, does not create each new utterance entirely from scratch but draws upon the resources made available by the shared Contextual Component. This offers an explanation not only for the many repetitions, overlaps, parallelisms, ellipses and other familiar properties of conversational language, but also for the very fluency of speech, which is a natural consequence of the availability of ready-made pieces of dialogue at all levels of analysis.

Psycholinguistic findings may be relevant for one of the central questions that have arisen among FDG linguists about the Contextual Component: How much information does it contain? Connolly (2007, this volume) argues that, since so many contextual factors can in principle impinge on the form of an utterance, an extended model is called for which embraces all possible influences of context on grammatical form. From the viewpoint of grammar-building, however, the ancillary status of the Contextual Component within a theory of verbal interaction that gives pride of place to grammatical analysis means that every effort should be made to reduce the domain of such a component to the minimum required for the regulation of grammatical phenomena. The grammar and its associated components constitute knowledge. That knowledge plays a role in the cognitive processes of language production and comprehension. These, in turn, call upon a range of further cognitive processes, notably 
the various kinds of memory. The Contextual Component could be equated with shortterm memory for grammatical information. All other kinds of memory - procedural memory for how to do things, including speaking and understanding, semantic or encyclopaedic memory for factual information or episodic memory for experiences are not specifically linguistic and thus should not be modelled within the four components of FDG. Interpretation, in the sense of the derivation of a personal meaning from the result of decoding and reconstruction, involves an interaction between linguistic and non-linguistic information and thus also is a process that lies beyond the model. Inference, finally, is a fundamental process within interpretation but it, too, is a more general cognitive ability: We can infer not just from words but also from gestures, facial expressions and even states of the world. All in all, then, there is much to be said in favour of a parsimonious Contextual Component within a theory of language that plays a role within a complex of cognitive processes. Analogously, from a psycholinguistic viewpoint, the influence of contextual factors is also subject to restrictions: Here the emphasis is on keeping them to a level at which they are processable within the rigorous time constraints of dialogue.

The question of the extent of contextual factors has been vigorously debated in the psycholinguistics of dialogue, in ways that are relevant for the cognitive adequacy of a dialogic FDG model. The fundamental question there is "Do people need elaborate mental models of their conversational partners in order to coordinate, or can they rely on less elaborate cues?" (Schober and Brennan 2003: 134). After all, even the use of the definite article the has been ascribed to the speaker's mental model of what she takes the hearer to perceive as physical co-presence, linguistic co-presence or community comembership (Schober and Brennan 2003: 135), each of these concepts itself being subject to complex subclassification, with the additional danger of infinite regress, since the hearer must also believe that the speaker is indeed taking him to have the necessary perceptions, and she must believe that he has those beliefs, etc. etc. This position we may characterize as partner-adjusted processing. An alternative position has emerged, known as 'egocentric processing, ${ }^{8}$ based on the insight that if a particular formulation is easier for an addressee to process, this does not entail that the speaker was actually trying (in a subconscious sense, of course) to make the addressee's task easier. In fact, she may have been trying to make the production task easier for herself. Schober and Brennan survey a vast array of inventive psycholinguistic experiments, which suggest evidence for both partner-adjusted and egocentric processing, depending on the phenomenon being focused on, on the individual being tested, etc. Their conclusion is devastating: "When there is a model of a partner's characteristics or beliefs, we don't know how elaborate or coherent it is, nor what role it plays in cognition in general. We don't know exactly how detailed the representation is, how specific it is to an individual, or how often it is updated" (Schober and Brennan 2003: 155).

\footnotetext{
${ }^{8}$ Freek Van de Velde (p.c.) has pointed out to me that, as shown by Levinson (2000: $27 \mathrm{ff}$.), the bottleneck in communication lies on the production side, with speakers having only limited capacity for producing utterances when compared with the hearer's capacity for processing: Speeding up recorded speech to twice or three times normal speed does not result in unprocessability (a fact which Levinson takes to bolster his argument that speakers rely heavily on inferencing).
} 
Psycholinguistics thus appears not to offer much certainty to linguists in search of backup from processing for their model-building.

More recent work by Arnold (2008), however, surveys experimentation suggesting that partner-adjusted and egocentric processing are not alternative modes of communicating but that for many situations it is immaterial whether a speaker's behaviour is interpreted as being in the addressee's or her own interests. After all, she argues,

the communal nature of discourse means that speakers can frequently assume that whatever is in their own focus of attention is also in the focus of attention of their addressee, and that gradations in accessibility, as indicated by the discourse, should be similar for all discourse participants. This offers the possibility of an efficient production system: speakers could simply refer to their own mental model of the situation for the purpose of calculating the mental accessibility of any particular referent (Arnold 2008: 504).

The picture that emerges here is that egocentric processing is partner-adjusted processing, as would follow from the adoption of a shared Contextual Component in a dialogic FDG. Of course, there will remain differences between participants A and B in a dialogue, such that misunderstandings or ambiguities may arise. But in practice, as we shall see instantiated in Section 6, where these occur in dialogic interaction they are cleared up by negotiation and reformulation and typically pass unnoticed by the conscious mind.

\section{Extracts from a conversation analysed from a dialogic viewpoint}

In order to further understand and exemplify the workings of a dialogic Contextual Component in FDG, let us consider some extracts from the transcription of a threeparticipant conversation taken (with removal only of indications of overlap) from Eggins and Slade (2005: 67-71). Although Eggins and Slade do discuss many aspects of this conversation, the points they select for discussion generally do not coincide with the concerns of the present paper. The three participants are Australians, Brad (a 27year-old student) and his parents, Dave and Fran, in their fifties. The conversation takes place in the family car. The full modified transcription is found in the Appendix. Note that each turn is divided into 'clauses'; for FDG purposes, we will do better to regard these as (typically) expressing Discourse Acts.

Let us begin by considering (1), which shows Turns 1 to 5:

$$
\begin{array}{lll}
\text { Turn } & \multicolumn{2}{c}{\text { Speaker }} \\
1 & \text { Brad } & \text { (i) Look } \\
& \text { (ii) See that guy } \\
& \text { (iii) He plays the double-bass } \\
2 & \text { Fran } & \begin{array}{l}
\text { Does he? } \\
\text { (i) In the orchestra } \\
\text { (ii) He's a funny bastard } \\
\text { (iii) And his wife's German }
\end{array} \\
& \text { Brad } & \text { (iv) And she's insane } \\
& \text { Dave } & \text { [coughs] }
\end{array}
$$




$\begin{array}{lll}4 & \text { Fran } & \begin{array}{l}\text { (i) He's funny } \\ \text { (ii) And she's insane? }\end{array} \\ 5 & \text { Brad } & \text { ALL Germans are insane }\end{array}$

In Turns 1 and 3, Brad performs seven Discourse Acts, the first with Imperative Illocution, the second with Interrogative Illocution and the remaining five with Declarative Illocution. Fran, in Turns 2 and 4, performs three Discourse Acts. In Turn 2, the purpose of her Discourse Act is merely to show interest and therefore counts as a backchannel (and not as a substantive contribution to the dialogue); although formally 'interrogative', there is arguably no Interrogative Illocution here. Note that the form taken by the turn (Does he?) is entirely predictable from the preceding discourse and thus can better be seen as a matter of the Morphosyntactic Component reacting to an indication of backchannelling (with no Communicated Content) at the Interpersonal Level.

Of greater interest to our present concerns is Fran's second intervention, Turn 4, in which her communicative intention (as registered in the Conceptual Component) is to ask a double question (doubting what her son has said or wanting evidence for his statements). The morphosyntactic form is, however, not that associated with an Interrogative Illocution, although the phonological form, with a rising intonation, is. Morphosyntactically, she mimics Brad's 'He's a funny bastard' as 'He's funny' (note that throughout the interaction Fran avoids the imprecations of the males); the declarative form can thus be analysed as involving the copying, with self-censorship, of the Communicated Content and the Propositional Content from the shared Contextual Component to the Interpersonal Level, as well as an (expurgated) copy from the Morphosyntactic Stratum. The presence of the Interrogative Illocution shows up in the rising intonation pattern of the Intonational Phrase he's funny. In the case of the second component of Turn 4, there is an exact copy of Communicated Content, Propositional Content and Morphosyntactic form, the only difference again being phonological (rising intonation). The effect of priming also shows up in Turn 5: Making a joke (presumably), Brad combines two elements already activated (German and insane). What is apparent here, then, is how in conversation there is an alternation between creative use of language (in the description of the musician and his spouse) and echoic mimicking through interpersonal alignment; Brad's final remark may be not so much an insult to Germans as an expression of togetherness in the family setting. to 69 :

The interplay between creative and primed content is also apparent in Turns 64
$64 \quad \operatorname{Brad}$
(i) He sits
(ii) He sits in a room and, and ... and th'
(iii) and decides
(iv) "I think therefore I am" ...
(v) All this stuff
(vi) An', I mean he hasn't got anything better to DO ... um
65 Fran He's an abstract thinker
66 Brad (i) Yeah, but ...
(ii) At least he could think abstractly about something that was worth thinking about, like soil erosion or something
Fran [laughs] 
67 Brad That's what I'm thinking

68 Fran How to solve the problem

69 Brad (i) I'm wondering these days

(ii) I'm thinking

(iii) What the hell ... use is anything I'm doing at University?

In Turn 64 Brad is struggling to explain why he thinks Descartes is an idiot. Fran answers in Turn 65 that Descartes is an abstract thinker. In FDG terms, although the Morphosyntactic Level (ML) shows a regular sequence of Determiner, Adjective and head Noun, at the Representational Level (RL), abstract modifies not the noun thinker but just the verb think, i.e. as shown in (3): ${ }^{9}$

$$
\begin{aligned}
& \operatorname{RL}:\left(\mathrm{x}_{\mathrm{i}}:\left(\mathrm{f}_{\mathrm{i}}:\left[\left(\mathrm{f}_{\mathrm{j}}: \operatorname{think}_{\mathrm{V}}\left(\mathrm{f}_{\mathrm{j}}\right)\right):\left(\mathrm{f}_{\mathrm{k}}: \operatorname{abstract}_{\text {Adj }}\left(\mathrm{f}_{\mathrm{k}}\right)\right)\right]\left(\mathrm{f}_{\mathrm{i}}\right)\right)\left(\mathrm{x}_{\mathrm{i}}\right)\right) \\
& \text { ML: }\left(\mathrm{Np}_{\mathrm{i}} \text { : [(Gwi } \text { : INDEF.SG }\left(\mathrm{Gw}_{\mathrm{i}}\right)\right)\left(\operatorname{Adjw}_{\mathrm{i}} \text { : abstract }\left(\mathrm{Adjw}_{\mathrm{i}}\right)\right)\left(\mathrm { Nw } _ { \mathrm { i } } \text { : } \left[\left(\mathrm{Vs}_{\mathrm{i}} \text { : think }\left(\mathrm{Vs}_{\mathrm{i}}\right)\right)\right.\right. \\
& \left.\left.\left.\left.\left(\operatorname{Aff}_{\mathrm{i}}: \operatorname{er}\left(\mathrm{Aff}_{\mathrm{i}}\right)\right)\right]\left(\mathrm{Nw}_{\mathrm{i}}\right)\right)\right]\left(\mathrm{Np}_{\mathrm{i}}\right)\right)
\end{aligned}
$$

In Turn 66, the relationship of modification that has been stored at the Representational Stratum reappears in Brad's think abstractly, which has the same representational structure $^{10}$ as has been stored from his mother's preceding utterance, namely:

$\left(f_{\mathrm{i}}:\left[\left(\mathrm{f}_{\mathrm{j}}: \operatorname{think}_{\mathrm{V}}\left(\mathrm{f}_{\mathrm{j}}\right)\right):\left(\mathrm{f}_{\mathrm{k}}: \operatorname{abstract}_{\text {Adj }}\left(\mathrm{f}_{\mathrm{k}}\right)\right)\right]\left(\mathrm{f}_{\mathrm{i}}\right)\right)$

[stored in Contextual Component]

$\left(\mathrm{f}_{\mathrm{l}}:\left[\left(\mathrm{f}_{\mathrm{j}}: \operatorname{think}_{\mathrm{V}}\left(\mathrm{f}_{\mathrm{j}}\right)\right):\left(\mathrm{f}_{\mathrm{k}}: \operatorname{abstract}_{\text {Adj }}\left(\mathrm{f}_{\mathrm{k}}\right)\right)\right]\left(\mathrm{f}_{\mathrm{l}}\right)\right)$

[used in subsequent utterance]

We observe, in addition, that Brad uses thinking as a gerund in Turn 66, as a complement of the relational adjective worth. The presence of this word form in the Morphosyntactic Stratum may well be what justifies the unusual presence of the progressive I'm thinking in the subsequent turn rather than the more usual That's what I think, often used in conversation to underscore a possibly controversial opinion. Although there may be some disparity between Descartes' thinking and that of a confused student (!), the priming effect of the morphosyntactic form is a plausible explanation for the unusual formulation, one that is regularized in Turn 69 in I'm wondering these days. See Mackenzie (2012) for further instances of priming effects 'overruling' grammatical regularities.

The end of passage (2) contains an instance of one speaker attempting to complete the utterance of another, here cited as (5):

$$
\begin{array}{lll}
67 & \text { Brad } & \text { That's what I'm thinking } \\
68 & \text { Fran } & \text { How to solve the problem }
\end{array}
$$

This kind of behaviour is taken by students of dialogue to be strong evidence for interpersonal alignment, because it shows speakers jointly working on creating meaning (Poesio and Rieser 2010: 1-2). Brad has not yet confessed that he has severe doubts about the value of his studies, and his mother here completes his utterance in a more

\footnotetext{
${ }^{9}$ For the analysis of agentive nominals in FDG, see Hengeveld and Mackenzie (2008: 217).

${ }^{10} \mathrm{I}$ assume that the suffix $-l y$ is attached at the Morphosyntactic Level in response to the presence of think as a verb.
} 
optimistic vein than he himself has in mind. ${ }^{11}$ Brad ignores his mother's turn, however, and orients the following turn to his self-doubts. Fran's response - she clearly hopes that he will continue with his studies - links up grammatically with Brad's last utterances (even if ...). Consider extract (6):

(6) 70
70 Fran
But even if it meant you could understand people and therefore HELP them?
71 Brad (i) Yeah, but I don't LIKE people ... umm
(ii) I don't want to be INVOLVED with people
(iii) I'd rather be involved with soil erosion
72
Fran
(i) Everybody has to be though

In this passage, which shows many lexical signs of mutual alignment (people, involved with, ...), Fran's Turn 72 links back to Brad's Turn 71 (ii); although in terms of recency Turn 72 would seem to suggest that Fran believes everybody has to be involved with soil erosion, it is clear from the dominance of people in the shared Contextual Component that what she means is involvement with people (cf. Eggins and Slade 2005: 90 for the same interpretation of Turn 72). This indicates that phenomena such as grammatical ellipsis (as seen in Turn 72) are sensitive not simply to stacking (cf. Hengeveld and Mackenzie, this volume) but also to priming, in this case by the oftrepeated element people.

Ellipsis itself provides further sustenance for a dialogue-based approach, since the absent material is typically understood by the hearer on the basis of what is in the shared Contextual Component, whether it originates from the speaker's or the hearer's previous Discourse Acts. Consider the following passage (also discussed under the heading of ellipsis in Eggins and Slade 2005: 93):

Brad That guy that that Bangladeshi that used to live with us he was a a Limnologist or whatever it's called

101 Fran A WHAT?

102 Dave Who?

103 Brad Oh not Limnologist

104 Fran Ichthyologist

In Turn 100, Brad enters the lexical item Limnologist into the shared context; this is immediately questioned by Fran, while Dave has forgotten the individual to whom the description 'Bangladeshi that used to live with us' applies. Brad in Turn 103 signals that his choice of lexical item was wrong with an elliptical utterance Oh not Limnologist which is then also picked up elliptically by Fran, so that 103 and 104 yield the jointly constructed propositional content 'He was not a limnologist but he was an ichthyologist'. Notice that the ellipsis in 103 depends on material that the speaker introduced into the Contextual Component (Brad 100), whereas the ellipsis in 104 is based on what the hearer produced (Fran, 101). For the grammatical operation of

${ }^{11}$ This is a typical instance of how there is a single shared Contextual Component but distinct Conceptual Components, with each participant in the dialogue having his/her own communicative intentions. 
ellipsis, however, with its reliance on a shared Contextual Component, this is immaterial.

One of the most salient effects of mutual alignment is in the area of the lexicon. Consider the following passage:

(8) $86 \quad$ Fran But whadda they know about education?

87 Brad Well they know

88 Fran What do fish gotta do with education?

$89 \quad$ Brad (i) Who says

(ii) They know anything about FISH

(iii) Just because they were administering fisheries?

In (8) Fran and her son are discussing the possibility of his seeking a career in administration in education, since she knows of people who have moved from administration in fisheries to similar work in education. In this brief passage, we find three occurrences of know sth. about sth. (Turns 86, 87 and 89 (ii)), themselves primed by earlier occurrences (Turns 76 (ii) and 82 (iii); see Appendix), two of fish as well as occurrences of administering and fisheries from several earlier turns (see Appendix), and two questions with the form What ... education? This kind of mutual borrowing of words, constructions and Configurational Properties is endemic in dialogue and most readily explained by assuming a shared pool of lexical and configurational resources held in the shared Contextual Component.

Another observation by students of interpersonal alignment is that the information offered in linguistic form need not be complete, as long as it is sufficient to permit an adequate basis for continuing interaction (Poesio and Rieser 2010: 4). This is clearly the case in (9) where Brad, in a long turn, is trying to explain about one of the courses he is following:
41
$\operatorname{Brad}$
(i) It's [laughing]
(ii) It's bloody
(iii) It's ... introductory philosophy ... sort of stuff
(iv) It's it's called ...
(v) Dunno
(vi) What it's called
(vii) Th' They've got weird names like 'The Pursuit of Human Rationality' or 'Self and Society'
(viii) And I, the one
(ix) I think the one that's that's all right is called Human Rationality
(x) And it's just introductory philosophy
(xi) They talk about ... Rationalism an' [belches] aaa [laughing]

In Turn 41 (xi) he clearly senses that he has given enough information to enable the conversation to continue and his meandering account ends not in a complete clause but in an eructation and a guffaw; the result is, however, clearly satisfactory to his parents.

Alignment does not always guarantee perfect understanding. This is apparent from Turns 20 to 25 and 31 to 32, shown as example (10):

(10) 20 Dave When are you gonna do ... all your odds 'n sods subjects?

21 Brad Whaddya mean "odds 'n sods subjects"? 


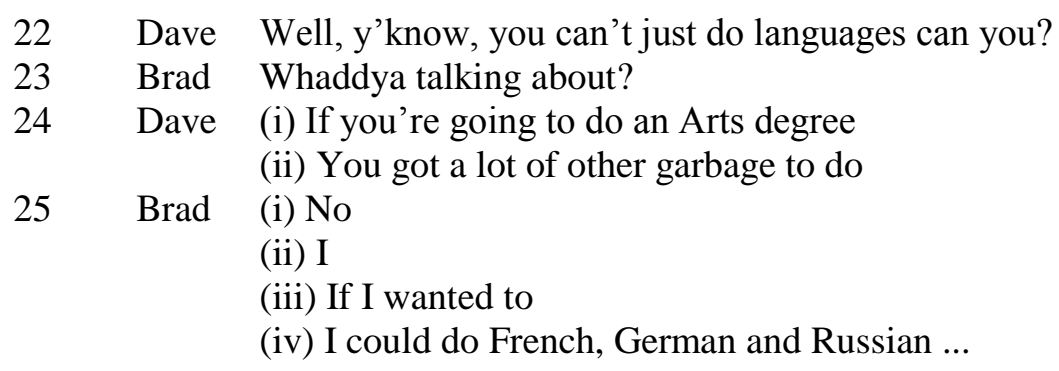

$\begin{array}{lll}31 & \text { Brad } & \text { (i) In an Arts degree } \\ & \text { (ii) As long as you do ... a few General Studies subjects } \\ 32 & \text { Dave } & \text { (i) That's what I mean } \\ & \text { (ii) And when are you gonna do your General Studies? }\end{array}$

In Turn 21, Brad explicitly indicates that he doesn't understand what his father means by odds ' $n$ sods subjects (held in the shared Contextual Component). In Turn 22, Dave tries to explain, but Brad (Turn 23) still doesn't understand - with reuse of the form Whaddya now not for 'What do you' but for 'What are you', arguably an indication of phonological auto-priming. Dave attempts to clarify in Turn 24, but Brad, to judge by Turn 25, apparently still doesn't understand that his father is using other garbage to mean subjects other than languages. It is not until Brad mentions General Studies in Turn 31 that Dave can finally establish common ground with his son (in Turn 32). It is arguable that Dave here, perhaps because he is unfamiliar with the exact title of the nonlinguistic courses, is indulging in egocentric processing: The expressions odds 'n sods subjects, can't just do languages, other garbage fail to create mutual understanding, which is ultimately achieved by chance, when Brad mentions the official name with which he, again using egocentric processing, is familiar. The temporary failure to communicate does not undermine the process of mutual alignment and does not jeopardize the continuance of the conversation; rather the entire incident passes unnoticed and uncommented.

There is a moment in the dialogue, however, at which the establishment of common ground is briefly a topic of conversation, in Turns 49 to 52:
49 Brad (i) You only have to do ...
(ii) I onl' ... oh [3-second pause]
(iii) I've told you about what POINTS are haven't I?
50 Dave Yeah
51 Fran Mmm
52 Brad (i) Right

Brad is in full flow when he drops all anchors, appearing to realize that his parents may not know what 'points' are, a concept which must have arisen in his advance planning. His third Discourse Act and the responses in Turns 50 and 51 act as a check on mutual understanding of the concept before Brad acknowledges the achievement of common ground in Turn 52 (i) and then can progress to give more detailed information. Again, it 
is noticeable that this check occurs smoothly, without breaking the fluency of the conversation.

The foregoing discussion of eight extracts from the three-party conversation has shown various ways in which the shared Contextual Component collaborates with the Grammatical Component. We have seen how lexical and grammatical material, rather than always being created afresh, can be copied from shared contextual storage for reuse or can be left unmentioned under ellipsis. Examples have been found of the Contextual Component overruling certain grammatical operations and of priming effects interfering with the stacking taken to characterize the storage of earlier utterances. The dialogic nature of grammatical competence has also been apparent in the joint production of utterances as well as in the abandonment of utterances that are already sufficiently understood. Temporary malfunctions of the shared Contextual Component are, as we have seen, fixed unproblematically through mutual negotiation that does not interfere with the coherence of the conversation. Finally, lexical usage has repeatedly been shown to involve a substantial element of repetition.

\section{Conclusion}

The proposal central to this paper has been that the Contextual Component can most convincingly be understood as part of an FDG that models dialoguing interactants rather than an isolated 'speaker'. The preceding argument has been inspired by a growing movement in discourse analysis and psycholinguistics towards the position that language production and comprehension are essentially collaborative processes, in which the production of each interactant is subject to priming from their own or their partner's earlier formulation and encoding choices, creating a situation of interpersonal alignment that is the foundation for satisfactory conversation. The result is a model of FDG which, while retaining all the sophistication of the model oriented to the individual, is inherently dialogic and in which the Contextual Component is explicitly shared by all participants in the interaction. The analysis of segments of a conversation has exemplified how such a model can clarify properties of language in use through an appeal to both the detail of the various levels of grammatical analysis and notions such as priming and interpersonal alignment as used in contemporary psycholinguistics.

\section{Appendix}

$\begin{array}{lll}\begin{array}{l}\text { Turn } \\ 1\end{array} & \begin{array}{l}\text { SpeakerText } \\ \text { Brad }\end{array} & \begin{array}{l}\text { (i) Look } \\ \text { (ii) See that guy } \\ \text { (iii) He plays the double-bass }\end{array} \\ 2 & \text { Fran } & \begin{array}{l}\text { Does he? } \\ \text { (i) In the orchestra } \\ \text { (ii) He's a funny bastard } \\ \text { (iii) And his wife's German }\end{array}\end{array}$


(iv) And she's insane

[coughs]

(i) He's funny

(ii) And she's insane?

ALL Germans are insane

$5 \quad$ Brad

(i) You know

(ii) You know a lot of funny people don't you Brad?

$7 \quad$ Brad

(i) Yeah

(ii) Everyone at Uni is

They're ALL mad

They're all FREAKS

Except you

Yeah

And they're all coming home now

(i) Whaddya mean?

(ii) Coming, oh

Like, they're coming up the hill are they?

14 Fran

15 Brad

(i) No, this

(ii) For General Studies we've got this ... tutor

(iii) And he's German

(iv) And he's insane

(i) I didn't know

(ii) You had to do General Studies

(i) Yeah I

(ii) I got exemption from $=$ [noise of passing bus $]$

(iii) Bastards!

Last year

From half of it

When are you gonna do ... all your odds 'n sods subjects?

Whaddya mean "odds 'n sods subjects"?

Well, y'know, you can't just do languages can you?

Whaddya talking about?

(i) If you're doing an Arts degree

(ii) You got a lot of other garbage to do

(i) $\mathrm{No}$

(ii) I

(iii) If I wanted to

(iv) I could do French, German and Russian ...

This year?

In first year

Oh this year

(i) I could do

(ii) In FIRST year you can do whatever you WANT =

$\mathrm{Mmm}$

(i) In an Arts degree

(ii) As long as you do ... a few General Studies subjects

(i) That's what I mean

(ii) And when are you gonna do your General Studies?

I'm doin' it NOW!

$\mathrm{Mmm}$

That's what I'm talking about

And what are your General Studies subjects?

36 Dave

$37 \quad$ Brad

38 Dave

(i) Oh it's ... RUBBISH

(ii) One of them is all right

(iii) One of them is actually good

Yeah but what is it? 


$\begin{array}{ll}39 & \text { Brad } \\ & \text { Fran } \\ 40 & \text { Dave } \\ 41 & \text { Brad }\end{array}$

42 Dave

43 Brad

44 Dave

45 Brad

$46 \quad$ Fran

$47 \quad$ Brad

48 Dave

49 Brad

50 Dave

51 Fran

$52 \quad$ Brad

$\begin{array}{ll}53 & \text { Fran } \\ 54 & \text { Brad } \\ 55 & \text { Fran } \\ 56 & \text { Brad } \\ & \\ 57 & \text { Fran } \\ 58 & \text { Brad } \\ & \\ 59 & \text { Fran } \\ 60 & \text { Brad } \\ & \\ 61 & \text { Fran } \\ 62 & \text { Brad }\end{array}$

(i) Well I'm thinking

(ii) What it is

[laughs]

History of Scotch bagpipe playing?

(i) It's [laughing]

(ii) It's bloody

(iii) It's ... introductory philosophy ... sort of stuff

(iv) It's it's called ...

(v) I dunno

(vi) What it's called

(vii) Th' They've got weird names like 'The Pursuit of Human Rationality' or 'Self and Society'

(viii) And I, the one

(ix) I think the one that's that's all right is called Human Rationality

(x) And it's just introductory philosophy

(xi) They talk about ... Rationalism an' [belches] aaa [laughing]

So you gotta pick all those up this year?

I'm doin' them ... at the moment!

Right

(i) It's look

(ii) it's just a ...

(iii) it's only a two hours a week subject

Mmm

And um

(i) But I thought

(ii) You dropped a lot of them last year

(iii) Which you were s'posed to do

(i) You only have to do ...

(ii) I onl' ... oh [3-second pause]

(iii) I've told you about what POINTS are haven't I?

Yeah

Mmm

(i) Right

(ii) So G' ...

(iii) First Year German is 12 points

(iv) You only have to do 8 points of General Studies in your whole in your whole career

Three years

Yeah

(i) Or whatever

(ii) Don't you?

(i) In $2^{\text {nd }}$ year you do ... 4 points

(ii) And in $3^{\text {rd }}$ year you do 4 points

Mmm

(i) If you wanted to

(ii) You could do ...

(iii) You could do ALL your points in one year

$\mathrm{Mmm}$

(i) But anyway you th'

(ii) it's it's just

(iii) it's just this rubbish subjects that you have to do

Mmm

(i) It's just a ... technicality

(ii) But this one on Philosophy is all right

(iii) We talk about bloody ... Descartes and all these idiots

(iv) It's riDICulous!

(i) Why are they ... idiots? 
(i) He sits

(ii) He sits in a room and, and ... and th'

(iii) and decides

(iv) "I think therefore I am" ...

(v) All this stuff

(vi) An, I mean he hasn't got anything better to DO ... um

$65 \quad$ Fran

He's an abstract thinker

$66 \quad$ Brad

(i) Yeah, but ...

(ii) At least he could think abstractly about something that was worth thinking about, like soil erosion or something

Fran

[laughs]

67 Brad

That's what I'm thinking

How to solve the problem

$\begin{array}{ll}68 & \text { Fran } \\ 69 & \text { Brad }\end{array}$

(i) I'm wondering these days

(ii) I'm thinking

(iii) What the hell ... use is anything I'm doing at University?

But even if it meant you could understand people and therefore HELP them?

71 Brad

(i) Yeah, but I don't LIKE people ... umm

(ii) I don't want to be INVOLVED with people

(iii) I'd rather be involved with soil erosion

(i) Everybody has to be though

(ii) But I mean

Or desalination

$73 \quad$ Brad

(i) Well, there's a

(ii) There's a go

(iii) Get yourself a a degree

(iv) And go and work for the Soil Con'

(i) Yeah but ...

(ii) Yeah, well, that's what I'd like to do

(iii) But I don't

76 Dave

(i) And they'd say

(ii) "Whaddya know about soil?"

(iii) And you'd say

(iv) "Well I can

(v) Know how

(vi) I know

(vii) What it's called in Russian."

(i) A degree in a degree in Linguistics isn't much use y'know

(ii) If you wanna work for Landcare or something

(iii) so

(iv) But anyway

Well you should have thought of that thought of that three years ago Brad

(i) I'll get a job

(ii) And I'll make some money

(iii) And then I'll maybe be able to do something meaningful (with my life)

(i) However, I mean what you said is is maybe all very true David

(ii) But, I mean, in the Public Area people are transferring from ... areas

Ah I don't want to be a bloody Public Servant

(i) No no but I'm just saying like

(ii) Like you're saying you know

(iii) You don't know anything about soil

(iv) But people are transferring from Fisheries to Education

(v) Now I can see no no bearing

Yeah but you can't teach if you haven't got a Diploma in Education

84 Fran

(i) They're not teaching though

(ii) But they're ADMINISTERing teachers 


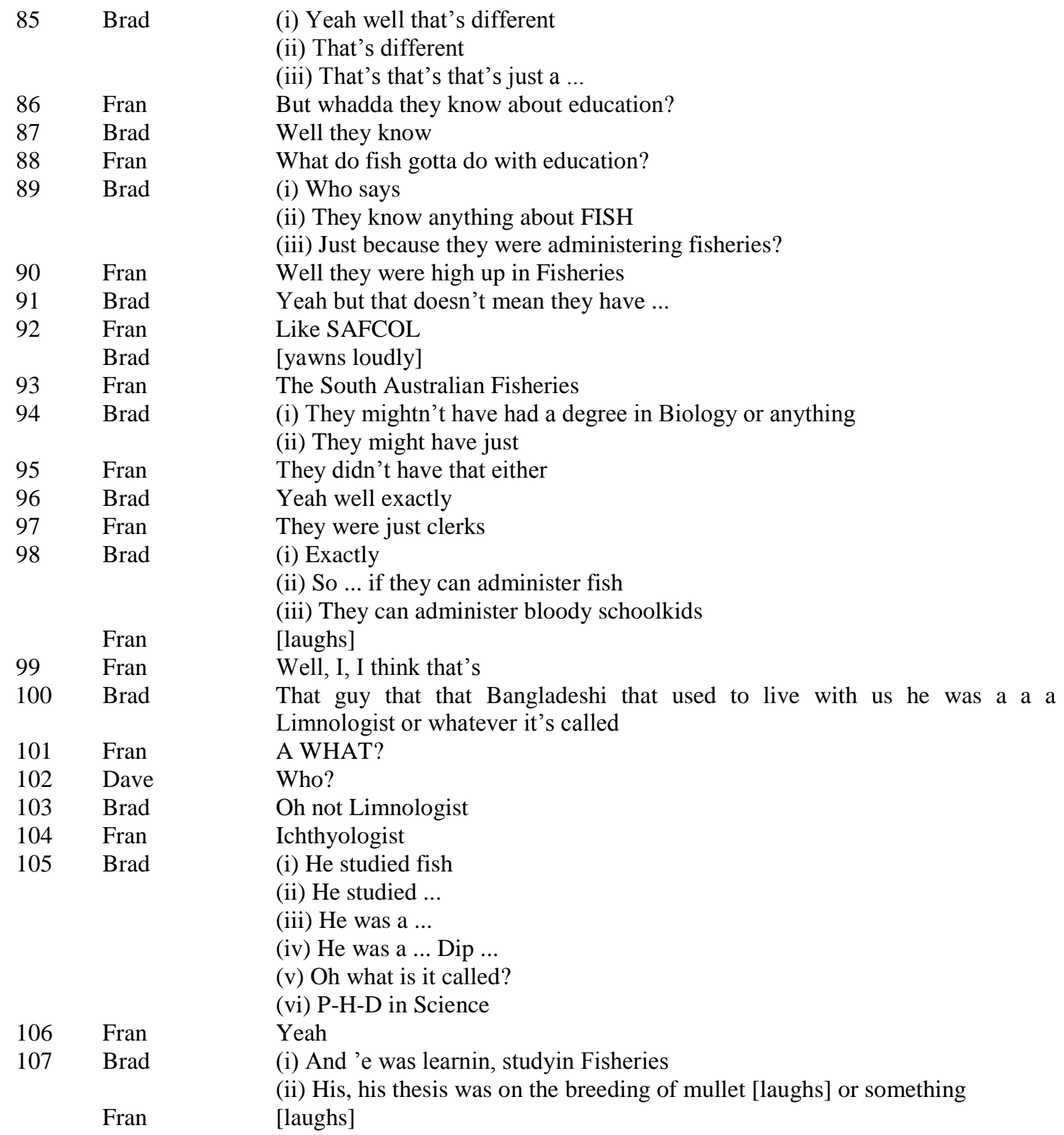

\section{References}

Arnold, Jennifer E. (2008) Reference production: Production-internal and addressee-oriented processes. Language and Cognitive Processes 23: 495-527.

Bakker, Dik (1999) FG expression rules: From templates to constituent structure. Working Papers in Functional Grammar 67. University of Amsterdam.

Bakker, Dik (2001) The FG expression rules: A dynamic model. Revista Canaria de Estudios Ingleses 42: $15-54$. 
Bakker, Dik (2005) Agreement: More arguments for the dynamic expression model. In Casper de Groot, and Kees Hengeveld (eds.), Morphosyntactic expression in Functional Grammar. Berlin and New York: Mouton de Gruyter, pp. 1-40.

Bargh, John (2006) What have we been priming all these years? On the development, mechanisms, and ecology of nonconscious social behavior. European Journal of Social Psychology 36: 147-168.

Bock, J. Kathryn (1996) Language production: Methods and methodologies. Psychonomic Bulletin and Review 3: 395-421.

Branigan, Holly P., Martin J. Pickering, and Alexandra A. Cleland (2000) Syntactic coordination in dialogue. Cognition 75: B13-B25.

Chomsky, Noam (1965) Aspects of the Theory of Syntax. Cambridge MA: MIT Press.

Clark, Andy (2008) Supersizing the Mind: Embodiment, Action, and Cognitive Extension. Oxford: Oxford University Press.

Clark, Herbert H. (1996) Using Language. Chicago IL: University of Chicago Press.

Clark, Herbert H., and Deanna Wilkes-Gibb (1986) Referring as a collaborative process. Cognition 22: 139.

Connolly, John H. (2007) Context in Functional Discourse Grammar. Alfa 51/2: 11-33.

Connolly, John H. (this volume) The Contextual Component within a dynamic implementation of the FDG model: Structure and interaction. Pragmatics 24.2: 229-248.

Eggins, Suzanne, and Diana Slade (2005) Analysing Casual Conversation. London: Equinox.

Ferreira, Victor S., and J. Kathryn Bock (2006) The functions of structural priming. Language and Cognitive Processes 21: 1011-1029.

Ford, Cecilia E., Barbara A. Fox, and Sandra A. Thompson (2002) Constituency and the grammar of turn increments. In Cecilia E. Ford, Barbara A. Fox, and Sandra A. Thompson (eds.), The language of turn and sequence. Oxford: Oxford University Press, pp. 14-38.

Giomi, Riccardo (this volume) Grammar, context and the hearer: A proposal for a hearer-based model of Functional Discourse Grammar. Pragmatics 24.2: 275-296.

Gómez González, María de los Ángeles (2011) Lexical cohesion in multiparty conversations. Language Sciences 33: 167-179.

Grice, H. Paul (1975) Logic and conversation. In Peter Cole, and Jerry Morgan (eds.), Syntax and semantics, vol 3. New York: Academic Press, pp. 41-58.

Halliday, M.A.K., and Ruqaiya Hasan (1976) Cohesion in English. London: Longman.

Hasson, Uri, Asif A. Ghazanfar, Bruno Galantucci, Simon Garrod, and Christian Keysers (2012) Brainto-brain coupling: A mechanism for creating and sharing a social world. Trends in Cognitive Sciences 16/2: 114-121.

Hengeveld, Kees (2005) Dynamic expression in Functional Discourse Grammar. In Casper de Groot, and Kees Hengeveld (eds.), Morphosyntactic expression in Functional Grammar. Berlin and New York: Mouton de Gruyter, pp. 53-86. 
Hengeveld, Kees, and J. Lachlan Mackenzie (2008) Functional Discourse Grammar: A TypologicallyBased Theory of Language Structure. Oxford: Oxford University Press.

Hengeveld, Kees, and J. Lachlan Mackenzie (this volume) Grammar and context in Functional Discourse Grammar. Pragmatics 24.2: 203-227.

Iacoboni, Marco (2005) Understanding others: Imitation, language, and empathy. In Susan Hurley, and Nick Chater (eds.), Perspectives on imitation: From neuroscience to social science. Vol. 1: Mechanisms of imitation and imitation in animals. Cambridge MA: MIT Press, pp. 77-99.

Iacoboni, Marco (2008). Mirroring People: The New Science of how we Connect with Others. New York: Farrar, Straus, and Giroux.

Isaac, Ellen A., and Herbert H. Clark (1987) References in conversations between experts and novices. Journal of Experimental Psychology: General 116: 26-37.

Kempson, Ruth, and Ronnie Cann (2007) Dynamic Syntax: Preliminaries for a dialogue-driven account of syntactic change. In Joseph C. Salmons, and Shannon Dubenion-Smith (eds.), Historical Linguistics 2005. Amsterdam and Philadelphia PA: John Benjamins Publishing Company, pp. 73-101.

Levelt, Willem J.M. (1989) Speaking. Cambridge MA: MIT Press.

Levelt, Willem J.M. (1999) A blueprint of the speaker. In C. Brown, and P. Hagoort (eds.), The neurocognition of language. Oxford: Oxford University Press, pp. 83-122.

Levinson, Stephen C. (2000) Presumptive Meanings: The Theory of Generalized Conversational Implicature. Cambridge MA: MIT Press.

Linell, Per (2007) Dialogicality in languages, minds and brains: Is there a convergence between dialogism and neuro-biology? Language Sciences 29: 605-620.

Mackenzie, J. Lachlan (2012) Cognitive adequacy in a dialogic Functional Discourse Grammar. Language Sciences 34: 421-432.

Pickering, Martin J., and Victor S. Ferreira (2008) Structural priming: A critical review. Psychological Bulletin 134/1: 427-459.

Pickering, Martin J., and Steven Garrod (2004) Toward a mechanistic psychology of dialogue. Behavioral and Brain Sciences 27: 169-226.

Poesio, Massimo, and Hannes Rieser (2010) Completions, coordination, and alignment in dialogue. Dialogue and Discourse 1. http://www.dialogue-and-discourse.org/, accessed 26 October 2011.

Schober, Michael F., and Susan E. Brennan (2003) Processes of interactive spoken discourse: The role of the partner. In Arthur C. Graesser, Morton A. Gernsbacher, and Susan R. Goldman (eds.), Handbook of discourse processes. Hillsdale NJ: Lawrence Erlbaum, pp. 123-164.

Tannen, Deborah (2006) Talking Voices: Repetition, Dialogue, and Imagery in Conversational Discourse. ( $2^{\text {nd }}$ edition.) Cambridge: Cambridge University Press.

Weigand, Edda (2010) Dialogue: The Mixed Game. Amsterdam and Philadelphia PA: John Benjamins Publishing Company. 
J. LACHLAN MACKENZIE, Ph.D. (Edinburgh), is Professor of Functional Linguistics in the Faculty of Humanities at the VU University Amsterdam as well as being a Researcher at the Instituto de Linguística Teórica e Computacional in Lisbon, Portugal. He is also Research Manager of SCIMITAR, an international team of researchers based in Santiago de Compostela, Spain, and editor of the international journal Functions of Language. In the past, he was Professor of English Language at the VU University Amsterdam. His current research interests are oriented to the development of Functional Discourse Grammar. He also works as a consultant for various universities and as an expert for EACEA, an agency of the European Commission.

Address: Faculty of Humanities, VU University Amsterdam, De Boelelaan 1105, 1081 HV Amsterdam, Netherlands. E-mail: lachlan_mackenzie@ hotmail.com 